\title{
PERBANDINGAN KINERJA ALGORITMA BIC, CUBIC DAN HTCP PADA TOPOLOGI DUMBBELL DAN SIMPLE NETWORK MENGGUNAKAN NS2
}

\author{
Rian Fahrizal ${ }^{1}$, Wahyu Dewanto ${ }^{2}$, Sujoko Sumaryono ${ }^{3}$ \\ ${ }^{1}$ Jurusan Teknik Elektro FT UNTIRTA \\ JIn. Jend. Sudirman Km 2 Cilegon Indonesia \\ 2,3 Jurusan Teknik Elektro FT UGM \\ Jln. Grafika 2 Yogyakarta 55281 INDONESIA
}

\begin{abstract}
High speed computer networks with a large waiting time is a common from of network in the future. In this network are commonly used TCP algorithms have difficullty in sending data. There are several algorithms that has used the BIC, CUBIC and HTCP. These algorithms needs to be tested to determine its performance when apllied to the network topology with two dumbbells, and simple network. Teh results obtained testing the algorithms is best HTCP performance by having the smallest value.
\end{abstract}

\section{Keywords : algorithms, BIC, CUBIC, HTCP}

Jaringan komputer kecepatan tinggi dengan waktu tunggu yang besar merupakan bentuk jaringan yang umum di masa depan. Pada jaringan ini algoritma TCP yang umum digunakan mengalami kesulitan di dalam melakukan pengiriman data. Ada beberapa algoritma yang telah digunakan yakni BIC, CUBIC, dan HTCP. Algoritma-algoritma ini perlu diuji untuk mengetahui kinerjanya jika diterapkan pada jaringan dengan dua topologi yakni dumbbell, dan simple network. Hasil pengujian didapatkan algoritma yang paling baik adalah HTCP dengan memiliki nilai kinerja yang paling kecil.

Kata kunci : Algoritma, BIC, CUBIC, HTCP

\section{PENDAHULUAN}

TCP/IP merupakan protokol yang digunakan secara luas di dalam jaringan Internet. Protokol ini memiliki beberapa lapisan yakni application layer, transport layer, network layer dan physical layer. Setiap layer ini memiliki fungsi yang berbeda antara satu dengan yang lainnya. Lapisan yang bertanggung jawab di dalam melakukan pengiriman data yang juga merupakan lapisan yang penting di dalam TCP/IP ini ialah transport layer. Ada dua motode yang digunakan di dalam layer ini yakni TCP dan UDP. Sebagian besar pengiriman data di dalam jaringan komputer menggunakan metode TCP.

Di dalam pengiriman TCP yang ada digunakan algoritma adaptive increase multiplicity decrease (AIMD). Di dalam algoritma ini penambahan jumlah data yang dikirim dalam satu kali pengiriman (window) jika data berhasil dikirim dan tidak mengalami kongesti. Apabila terjadi kongesti atau terjadi error maka pengiriman window berkurang setengahnya. Algoritma ini telah digunakan sejak tahun 1980-an hingga sekarang. Seiring perkembangan waktu jaringan Internet membutuhkan bandwidth yang jauh lebih besar. Algoritma AIMD ini mengalami masalah pada jaringan komputer dengan bandwidth lebih besar dari 1 Gbps. Hasil penelitian menunjukan dibutuhkan waktu yang lama untuk mencapai nilai badwidth 1 Gbps jika propagation delay pada jaringan tersebut memiliki nilai $100 \mathrm{~ms}$.

Untuk menangani masalah di dalam algoritma AIMD dibuat algoritma alternatif yang sudah diterapkan di dalam Linux kernel terbaru yakni BIC, CUBIC dan HTCP. Ketiga algoritma ini digunakan untuk menangani masalah pada jaringan Internet dengan waktu delay yang besar. Akan tetapi masih diperlukan pengujian yang baik yang dapat membuktikan bahwa ketiga algoritma ini merupakan algoritma yang terbaik yang dapat diterapkan di dalam jaringan komputer. Pengujian yang dilakukan untuk ketiga algoritma ini dilakukan dengan menggunakan topologi yang mencoba mensimulasikan jaringan Internet yang ada dengan menggunakan topologi dumbbell dan simple network.

Parameter kinerja yang digunakan di dalam pengujian ini ialah menggunakan rata-rata throughput, stabilitas dan fairness (Raj Jain index). Kemudian dari nilai-nilai parameter yang 
telah digunakan tersebut dilakukan perhitungan yang dapat menunjukan bahwa parameter tersebut bisa dibandingkan secara keseluruhan. Perhitungan tambahan ini menunjukan kinerja dari algoritma yang dibandingkan.

\section{DASAR TEORI}

\subsection{BIC-TCP}

Algoritma ini memandang pengendalian congesti merupakan sebuah masalah pencarian dimana sistem dapat memberikan jawaban ya/tidak sebagai umpan balik melalui paket yang hilang yang menunjukan bahwa nilai pengiriman lebih besar dari kapasitas jaringan. Nilai dari window minimum dapat ditentukan sebagai besarnya window yang mengalir yang tidak terdapat paket yang hilang. Apabila ukuran window maksimum diketahui, dapat diterapkan teknik pencarian biner untuk menentukan besarnya window yang dituju untuk mencapai nilai tengah maksimum dan minimum. Pada saat penambahan sampai ke nilai yang diharapkan, jika menghasilkan paket hilang, nilai window dapat ditentukan sebagai nilai maksimum baru dan megurangi besarnya window setelah paket loss dapat ditentukan sebagai minimum yang baru. Nilai antara kedua nilai ini merupakan nilai yang diharapkan.

Hubungan untuk pendekatan ini ialah bahwa ketika jaringan menghasilkan loss antara minimum baru tapi tidak terjadi terlalu dekat dengan nilai minimum yang baru, nilai yang diharapkan pasti berada diantara dua nilai. Sampai mencapai nilai yang diharapkan dan tidak menghasilkan paket hilang, maka besar nilai yang ada menjadi nilai minimum yang baru, dan nilai yang diharapkan dihitung kembali. Proses ini berulang dengan melakukan pembaharuan nilai minimum dan maksimum sampai perbedaan antara nilai-nilai tersebut mencapai nilai dibawah batas, yang disebut dengan penambahan minimum (minimum increament $\mathrm{S}_{\mathrm{min}}$ ). Teknik ini disebut dengan binary search increase.

Binary search increase menjadikan pencarian bandwidth menjadi semakin agresif ketika perbedaan antara window yang ada dengan window yang diharapkan besar, dan menjadi kurang agresif pada saat besarnya window yang ada mendekati besarnya window yang diharapkan. Teknik unik dari protokol ini ialah fungsi penambahannya dalam bentuk logaritmik, sehingga pada saat mendekati nilai saturasi besarnya penambahan window semakin berkurang. Protokol yang lain menambahkan nilai bandwidth sampai pada saat nilai saturasi sehingga penambahan nilai saturasi adalah nilai maksimum dari keadaan tersebut. Pada umumnya, jumlah paket yang hilang berbanding lurus dengan besarnya penambahan terakhir sebelum paket hilang. Oleh karena itu binary search increase dapat mengurangi paket yang hilang. Seperti yang diketahui, keuntungan utama dari binary search ialah dapat memberikan fungsi respon yang baik, yang dapat digabungkan dengan penambahan secara linear.

Untuk menjamin penyatuan yang lebih cepat dan RTT yang adil, digabungkan binary search increase dengan strategi penambahan linear. Pada saat jarak dari ukuran window dengan yang diinginkan terlalu besar, penambahan ukuran window secara langsung pada nilai tengah tersebut memberikan beban berat ke dalam jaringan. Pada saat jarak dari ukuran window yang ada dengan besarnya window yang diinginkan pada binary search increase lebih besar dari langkah maksimum yang disebut dengan penambahan maksimum (maximum increment $\mathrm{S}_{\max }$ ), ditambahkan nilai window dengan $\mathrm{S}_{\max }$ sampai jarak menjadi kurang dari $\mathrm{S}_{\max }$, pada saat dimana penambahan window secara langsung ke dalam nilai yang diinginkan. Kemudian setelah pengurangan window besar, menambahkan nilai window secara linear dan selanjutnya penambahan secara logaritmik. Penggabungan dari binary search increase dan penambahan secara penjumlahan disebut dengan binary increase.

Penggabungan dengan strategi pengurangan secara pembagian, binary increase menjadi mendekati penambahan linear dalam window yang besar. Hal ini disebabkan window yang lebih besar menghasilkan pengurangan yang lebih besar dengan pengurangan dengan perkalian, sehingga membutuhkan rentang waktu yang lebih lama. Kemudian di saat ukuran window kecil, menjadi binary search increase dengan rentang waktu penambahan yang lebih sedikit.

Dapat dilihat bahwa di dalam model loss yang telah tersinkironisasi secara penuh, binary search increase digabung dengan pengurangan secara pengali bergabung menjadi sebuah nilai throughput yang adil. Sebagai contoh ada aliran dengan ukuran window yang berbeda, tapi dengan RTT yang sama. Karena window yang berukuran lebih besar berkurang lebih banyak pada pengurangan secara perkalian (dengan factor yang tetap $\beta$ ), waktu untuk mencapai target lebih lama untuk window yang lebih besar. Akan tetapi, penggabungannya membutuhkan waktu yang lama. Pada penambahan binary increase, membutuhkan log(d)- 
$\log \left(\mathrm{S}_{\min }\right) \mathrm{RTT}$ untuk mencapai window maksimum setelah pengurangan window d. karena penambahan window dalam fungsi log, semakin besar window dan semakin kecil window dapat mencapai kembali nilai maksimumnya dengan sangat cepat pada waktu yang hampir bersamaan. Akan tetapi window yang lebih kecil mengalir dengan bandwidth yang lebih kecil dari yang lebih besar sebelum pengurangan window selanjutnya. Oleh karena itu dimodifikasi binary search increase sebagai berikut.

Dalam binary search increase, setelah pengurangan window, nilai maksimum dan minimum ditentukan. Contohnya nilai-nilai ini adalah max_win $n_{i}$ dan min_win m $_{i}$ untuk aliran i $(i=1,2)$. Apabila nilai maksimum baru lebih kecil dari nilai sebelumnya, window ini memiliki tren penurunan. Kemudian diatur ulang nilai maksimum baru menjadi sama seperti nilai window yang diinginkan baru, dan selanjutnya diatur lagi nilai tujuan. Kemudian diterapkan penambahan binary increase normal. Bentuk strategi ini disebut convergence.

BIC-TCP menggunakan bentuk algoritma pencarian biner untuk memperbaharui $c w n d$. Nilai dari $w_{1}$ dipelihara yang menentukan nilai setengah antara nilai $c w n d$ sebelum dan setelah kejadian kehilangan terakhir. Aturan pembaharuan cwnd mencari dengan cepat penambahan cwnd pada saat hal ini mencapai jarak tertentu $S_{\max }$ dari $w_{1}$, dan memperbaharui $c$ wnd lebih lambat ketika nilainya mendekati $w_{1}$. Perkalian backoff dari $c w n d$ digunakan pada pendeteksian paket yang hilang, dengan asumsi faktor backoff $\beta$ sebesar 0,8 . Secara rinci,

$$
\begin{gathered}
\text { Ack: }\left\{\begin{array}{r}
\delta=\left(w_{1}-c w n\right. \\
c w n d-c w n d+1
\end{array}\right. \\
\text { Loss: }\left\{\begin{array}{c}
w \\
1=\left\{\begin{array}{l}
\frac{1+g}{1} w w d \\
\text { awd }
\end{array}\right. \\
w_{2}=c w n d \\
\text { cwnd }-\beta x c
\end{array}\right.
\end{gathered}
$$

Dengan

$$
f_{\mathrm{s}}(\delta, \text { cwnd })\left\{\begin{array}{lr}
\frac{\bar{a}}{\sigma} & (\delta \leq 1, \text { cwn } \\
& \text { atau }\left(w_{1} \leq \text { cwnd }<w_{1}+\right. \\
\delta & 1<\delta \leq S_{\max }, c w n c \\
\frac{w_{1}}{E-1} & B \leq \text { cwnd }-w_{1}<S_{\max } \\
S_{\max } & \text { se }
\end{array}\right.
$$

(2.18)

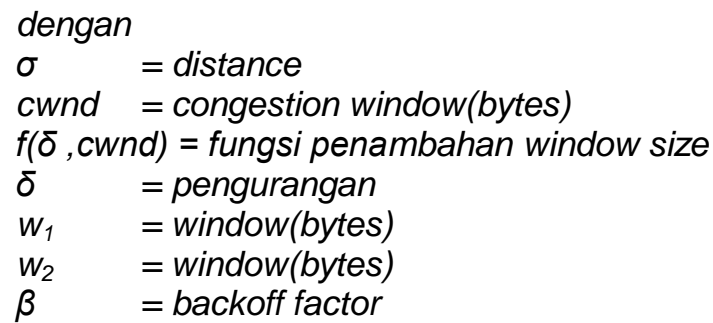

BIC-TCP juga menerapkan sebuah algoritma dimana pada saat utiliasasi rendah terdeteksi, akan menambahkan window lebih agresif. Hal ini dikendalikan dengan parameter Low-Util dan Util_Check. Untuk menentukan kompabilitas sebelumnya, hal ini menggunakan parameter pembaharu TCP standar dimana cwnd dibawah batas Low-Window.

\subsection{CUBIC}

Seperti namanya fungsi penambahan window yang digunakan ialah fungsi cubic yang memiliki kesamaan dengan fungsi penambahan BIC-TCP. CUBIC menggunakan fungsi cubic untuk waktu yang berlalu dari kejadian congesti yang terakhir. Walaupun sebagian besar algoritma alternative menggunakan fungsi penambahan convex dimana setelah kejadian paket hilang, penambahan window selalu bertambah, CUBIC menggunakan bentuk concave dan convex dari fungsi cubic untuk penambahan window. 
Penjelasan lebih detail dari fungsi ini ialah setelah pengurangan window karena kejadian paket yang hilang, didaftarkan $\mathrm{W}_{\text {maz }}$ menjadi nilai window dengan munculnya kejadian window hilang dan menggunakan pengurangan dengan perkalian dari congestion window dengan menggunakan factor $\beta$ dengan $\beta$ adalah konstanta pengurangan window dan menggunakan algoritma recovery dan retransmit dari TCP. Kemudian setelah masuk ke algoritma congestion avoidance dari recovery, mulai ditambahkan window menggunakan bentuk concave pada fungsi cubic. Fungsi cubic ditentukan untuk memiliki nilai baru pada $\mathrm{W}_{\max }$ sehingga penambahan berlanjut sampai ukuran window menjadi $W_{\max }$. kemudian fungsi cubic berubah menjadi bentuk convex dan penambahan window convex dimulai. Bentuk penentuan window (concave dan selanjutnya convex) meningkatkan stabilitas protokol dan jaringan ketika mengatur utilisasi jaringan kecepatan tinggi. Hal ini disebabkan ukuran window hamper mendekati konstan, membentuk nilai baru dekat dengan $\mathrm{W}_{\max }$ dengan utilisasi jaringan tertinggi dan di dalam kondisi steady, sebagian besar ukuran window CUBIC mendekati $\mathrm{W}_{\max }$, sehingga mempromosikan stabilitas utilisasi jaringan kecepatan tinggi dan protokol. Protokol dengan fungsi penambahan convex menjadi memiliki penambahan window terbesar sekitar nilai saturasi, dengan paket yang hilang banyak.

Algoritma ini menggabungkan ide dasar dari High-Speed TCP dan H-TCP. Disebut dengan penambahan cwnd sebagai fungsi dari waktu karena pemberitahuan terakhir dari congesti, dan besarnya window pada pemberitahuan terakhir congesti. Bentuk dari algoritma ini dapat disimpulkan sebagai berikut:

Perubahan slow start. Perubahannya ditentukan pada awal. Sekali cwnd meningkat di atas ssthresh, CUBIC keluar dengan menggunakan algoritma slow start normal dan perubahan menggunakan penambahan eksponensial yang agresif dimana cwnd ditambahkan sebesar satu paket untuk setiap 50 ack yang diterima atau sama dengan dua kali $c w n d$ mendekati setiap 35 waktu round-trip.

Faktor backodd 0,8. Pada paket yang hilang, cwnd dikurangi dengan faktor 0,8.

Clamp pada laju penambahan maksimum. Laju penambahan pada operasi AIMD dibatasi paling tidak $20^{*}$ delay_min paket setiap RTT, dimana delay_min adalah perkiraan round-trip propagation waktu tunda dari aliran data. Merubah dari paket per RTT menjadi paket per detik, clamp ini kira-kira sama dengan laju penambahan 20 paket/detik tidak tergantung RTT.

Fungsi penambahan cubic. Subyek pada clamp ini, laju penambahan adalah paket target-cwnd per RTT. Perhatikan bahwa efek dari penambahan ini ialah menyesuaikan cwnd menjadi sama dengan target pada arah dalam RTT tunggal. Nilai dari target dihitung dari

$$
\begin{aligned}
& \text { target }=W_{\max }+C\left(t-\sqrt[3]{\left(\beta\left(W_{\max }-0,8 W^{2}\right)\right)^{2}}\right. \\
& \text { dengan } \\
& W_{\max }=\text { window maksimum(bytes) } \\
& W=\text { window(bytes) } \\
& t=\text { waktu (detik) } \\
& C=\text { cubic } \\
& \beta=\text { faktor pengurangan }
\end{aligned}
$$

dimana $\mathrm{t}$ adalah waktu berlalu sejak backoff terkahir (mendekati nilai delay_min ditambahkan ke dalam nilai ini) dan $\mathrm{W}_{\max }$ dihubungkan dengan cwnd pada backoff terkahir dan ditandai origin_point pada kode. W adalah nilai cwnd sebelum backoff terakhir, sehingga $0,8 \mathrm{~W}$ adalah nilai $c w n d$ nilai sebelum backoff muncul.

Adaptasi fungsi cubic. Nilai dari $\mathrm{W}_{\max }$ ditentukan tergantung dari apakah backoff terakhir muncul sebelum atau sesudah cwnd tercapai pada nilai $\mathrm{W}_{\max }$ sebelumnya. Atau jika tidak $\mathrm{W}_{\max }$ diset sama dengan $0,9 \mathrm{~W}$.

Algoritma ini juga mencakup kode untuk meyakinkan bahwa algoritma ini paling tidak seagresif seperti TCP yang ada.

\subsection{HTCP}

Metode pengaturan bandwidth dilakukan dengan melakukan penambahan window. Awal pengiriman data algoritma slow start dijalankan sampai mencapai nilai batas tertentu yang telah ditentukan. Setelah nilai tersebut tercapai maka algoritma ini dijalankan. Pada saat muncul kongesti nilai ambang batas menjadi setengah dari nilai sebelumnya yang digunakan pada pengiriman paket selanjutnya. 
HTCP menggunakan waktu lalu $\Delta \square$ sejak kejadian congesti terakhir, daripada cwnd, untuk menentukan jalur pada bandwidth-waktu tunda dan parameter penambahan AIMD berbeda sebagai fungsi $\Delta$. Parameter penambahan AIMD juga ditentukan dengan jalur waktu round-trip untuk mengurangi ketidak adilan antara aliran dengan waktu round-trip yang berbeda. Pengurangan faktor AIMD ditentukan untuk meningkatkan utilisasi jalur berdasarkan pada estimasi ketentuan queue pada jalur. Secara lengkap

$$
\begin{aligned}
& A C K: \quad \text { cwnd }- \text { cwnd }+\frac{2}{-} \\
& \text { Loss: cwnd }-g_{\beta}(B)
\end{aligned}
$$

Dengan

$$
f_{\alpha}(\Delta)=\left\{\begin{array}{l}
1 \\
\max \left(\bar{f}(\Delta) T_{\min }, 1\right)
\end{array}\right.
$$

$$
g_{p}(B)=\left\{\begin{array}{l|l}
0.5 & \mid \frac{\beta(\hat{t}+1)-}{E(\mathrm{k})} \\
\min \left(\frac{T_{\min }}{T_{\max }}, 0,8\right) & s e
\end{array}\right.
$$

dengan

$$
\begin{aligned}
& \text { cwnd } \quad=\text { congestion window(bytes) } \\
& \beta=\text { faktor backoff } \\
& \Delta \quad=\text { delta } \\
& f_{\alpha}(\Delta) \quad=\square \text { fungsi penambahan congestion window } \\
& g_{\beta}(B) \quad=\text { fungsi pengurangan congestion window } \\
& T_{\min } \quad \text { = waktu minimum(detik) } \\
& T_{\max } \quad \text { = waktu maksimum(detik) }
\end{aligned}
$$

dimana $\Delta_{\mathrm{L}}$ ditentukan batas sehingga algoritma update TCP standar digunakan dimana $\Delta \square \leq \Delta_{\mathrm{L}}$. Fungsi penambahan kuadrat untuk $\mathrm{f}_{\alpha}$ ialah

$$
f_{g}(\Delta)=1+10\left(\Delta-\Delta_{2}\right)+0,25(A
$$

dengan

$f_{\alpha}(\Delta) \quad=$ fungsi penambahan dalam rentang waktu

$\Delta_{L} \quad=$ Delta limit

$\mathrm{T}_{\min } \mathrm{T}_{\max }$ menghitung waktu round-trip yang telah ada. $\beta(\mathrm{k}+1)$ adalah perhitungan throughput yang dicapai maksimum pada masa congesti terakhir.

\section{METODE PENELITIAN}

\subsection{Topologi dumbbell}

Seperti yang terlihat pada Gambar 1., dimana node sumber (node 0,1,6,7) dan node penerima (node 4,5,8,9) terhubung melewati node 2 dan node 3 yang berfungsi sebagai router. Bandwidth antara node sama sebesar 1 Gbps. Pada detik ke-5 node 0 melakukan pengiriman data ke node 4, kemudian node 1 melakukan pengiriman data pada detik ke-15. Pada pengiriman data ke-3 dilakukan oleh node 6 ke node 8 pada detik ke-25, lalu node 7 melakukan pengiriman data ke node 9 pada detik ke-35. Pada detik ke-100 simulasi selesai.

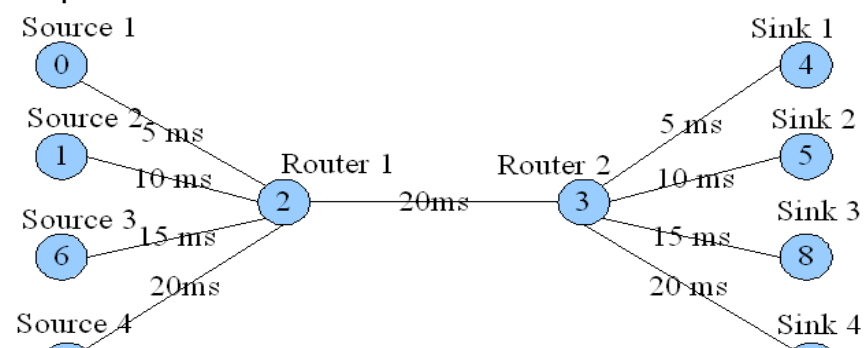

Gambar 1. Topologi dumbbell 
Program simulasi menggunakan algoritma , H-TCP, BIC dan CUBIC pada metode pengiriman data. Pada simulasi ini ada empat aliran data mengalir melalui satu link yang sama yakni dari link antara node 3 dan node 4, seperti yang ditunjukan pada Gambar 3.

Topologi ini memiliki dua bentuk yang digunakan untuk memudahkan di dalam analisis yakni dengan menggunakan nilai yang sama pada waktu tunggu untuk semua node yang melakukan pengiriman. Node yang melakukan pengiriman memiliki waktu pengiriman yang sama dengan scenario sebelumnya.

\subsection{Topologi Simple network}

Topologi simple network dapat dilihat pada Gambar 2. Pada konfigurasi ini, router inti menunjukan backbone jaringan dengan router perantara bertanggung jawab untuk node pengirim dan penerima terhubung dengan jaringan.

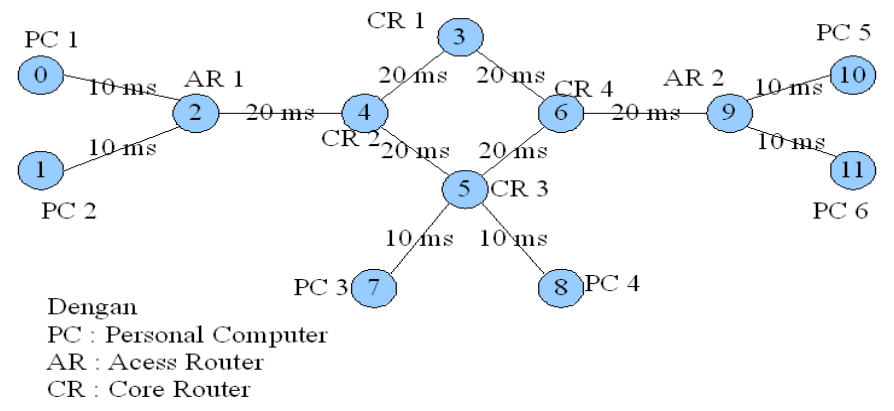

Gambar 2. Topologi Simple network

Pada topologi ini node 0,1 , dan 7 melakukan pengiriman data sedangkan node 8, 10, dan 11 menerima data yang dikirim. Topologi ini merupakan penyederhanaan topologi menggunakan transit dan stub [15].

Program simulasi menggunakan algoritma H-TCP, BIC dan CUBIC pada metode pengiriman data. Hubungan antara node dapat dilihat pada Gambar 2.

\section{ANALISIS HASIL SIMULASI}

\subsection{Analisis Topologi Dumbbell.}

Pada simulasi ini terdapat empat buah node yang melakukan pengiriman yang melakukan pengiriman secara bergiliran sampai detik ke-100. Ada dua bentuk scenario pada simulasi kali ini yang pertama meiliki waktu tunggu yang berbeda, sedangkan scenario yang kedua waktu tunggunya sama.

Simulasi ini menunjukan algoritma berhasil melakukan pengiriman, dimana keempat node yang melakukan pengiriman berhasil mengirim data. Sedangkan pada algortima BIC dan CUBIC hanya dua node yang berhasil melakukan pengiriman. Kemudian algoritma HTCP hanya berhasil melakukan pengiriman sebanyak 3 node.

Kemudian untuk pengujian pada topologi dumbbell yang meliputi dua pengujian yang sedikit berbeda dapat ditunjukan pada Tabel 1. dan Tabel 2. Walaupun pada pengujian topologi ini menggunakan sedikit metode yang sedikit berbeda hasil kinerja menunjukan perbedaan yang jauh pada algoritma tertentu.

Tabel 1. Hasil perhitungan kinerja algoritma topologi dumbbell pertama

\begin{tabular}{|l|c|c|c|c|}
\hline Algoritma & $y$ & $r$ & $z$ & $u$ \\
\hline BIC & 0.98825 & 0.076415 & 0.497368 & 1.562033 \\
\hline CUBIC & 0.998781 & 0.209982 & 0.541685 & 1.750448 \\
\hline HTCP & 0.504797 & 0.128989 & 0.288293 & 0.922079 \\
\hline
\end{tabular}

Tabel 2. Hasil perhitungan kinerja algoritma topologi dumbbell kedua

\begin{tabular}{|l|l|l|l|l|}
\hline Algoritma & $\mathrm{y}$ & $\mathrm{R}$ & $\mathrm{z}$ & $\mathrm{u}$ \\
\hline
\end{tabular}




\begin{tabular}{|l|l|l|l|l|}
\hline BIC & 0.987156 & 0.071837 & 0.496263 & 1.555256 \\
\hline CUBIC & 0.998813 & 0.206208 & 0.538122 & 1.743142 \\
\hline HTCP & 0.498344 & 0.293928 & 0.316936 & 1.109208 \\
\hline
\end{tabular}

Tabel 1. menunjukan algoritma yang paling baik adalah algoritma dengan nilai 0,14. Algoritma HTCP lebih baik dibandingkan algoritma BIC dan CUBIC dengan nilai 0,9. Algoritma BIC sedikit lebih baik dibandingkan dengan CUBIC dengan nilai 1,6, sedangkan algoritma CUBIC memiliki nilai kinerja 1,8 .

Seperti yang terlihat dari Tabel 1. sebelumnya pada Tabel 2. ini menunjukan algoritma yang terbaik, walaupun dengan nilai kinerja 0,7. Algoritma HTCP memiliki nilai kinerja 1,1 sedangkan algoritma BIC memiliki nilai 1,6, dan algoritma CUBIC memiliki nilai 1,7.

\subsection{Analisis Topologi Simple network}

Pengujian pada simulasi ini menunjukan bahwa keempat algoritma memiliki nilai yang selalu berubah-ubah hingga akhir simulasi. Akan tetapi algoritma BIC memiliki nilai akhir throughput yang tidak terlalu besar perbedaannya antara node-node-nya. Kemudian algoritma CUBIC membutuhkan waktu yang lama untuk mencapai nilai throughput yang mendekati stabil. Sedangkan algoritma HTCP tidak mencapai nilai yang stabil atau mendekati stabil hingga akhir simulasi. Pada algoritma terdapat kegagalan di dalam pengiriman pada node ketiga.

Hasil analisis kinerja algoritma pada pengujian topologi simple network dapat ditunjukan pada Tabel 3.

Tabel 3. Hasil perhitungan kinerja algoritma topologi simple network

\begin{tabular}{|l|r|l|l|l|}
\hline Algoritma & $\mathrm{y}$ & $\mathrm{R}$ & $\mathrm{z}$ & $\mathrm{u}$ \\
\hline BIC & 0.107054 & 0.292323 & 0.064604 & 0.463982 \\
\hline CUBIC & 0.202931 & 0.259688 & 0.126967 & 0.589586 \\
\hline HTCP & 0.137327 & 0.37138 & 0.111944 & 0.62065 \\
\hline
\end{tabular}

Berdasarkan Tabel 3. menunjukan bahwa algoritma BIC memiliki kinerja yang paling baik jika dibandingkan dengan algoritma yang lainnya yakni memiliki nilai 0,46. Kemudian algoritma yang terbaik kedua ialah algoritma CUBIC dengan nilai 0,59. Algoritma HTCP memiliki kinerja yang lebih baik jika dibandingkan dengan, algoritma HTCP memiliki nilai kinerja 0,62 . Algoritma memiliki kinerja yang paling buruk pada topologi ini dengan memiliki nilai 0,77 .

Dari pengujian yang dilakukan dapat dikatakan bahwa algoritma HTCP merupakan algoritma yang terbaik di dalam simulasi. Nilai kinerja memiliki nilai yang terkecil untuk pengujian secara keseluruhan. Hal ini menunjukan pengujian di dalam jaringan computer yang mencoba mensimulasikan jaringan Internet algoritma HTCP lebih baik jika dibandingkan dengan algoritma BIC dan CUBIC. 


\section{DAFTAR PUSTAKA}

Chiu D.M., Jain R., Analyis of the Increase and Decrease Algorithms for Congestion Avoidance in Computer Networks, Computer Networks and ISDN Sistems, 1989

Even B., An Experimental Investigation of TCP Performance in High Bandwidth-Delay Product Path, Thesis, Hamilton Institute, Maynooth, Ireland, 2007.

Ha S., Rhee I., CUBIC: A New TCP-Friendly High-Speed TCP Variant, International Workshop on Protocols for and Long Distance Networks, 2005.

Leith D., Shorten R., "H-TCP Protocol for High-Speed Long Distance Networks", PFLDnet, 2004.

Leith D., Shorten R.N., McCullagh G., "Experimental Evaluation of CUBIC-TCP, PFLDnet, 2007.

Rhee I., Xu L., CUBIC: A New TCP-Friendly High-Speed TCP Variant, North Carolina State University, University of Nebraska-Licoln, USA: 2004.

Tanenbaum A. S., Computer Network, Fourth Edition, Pearson Education International, Upper Saddle River, New Jersey, USA: Prentice Hall, 2003.

Xu L., Khaled H., Rhee I., Binary Increase Congestion Control for , Long Distance Networks, Paper, North Carolina state University, Releigh, NC, USA, 2003.

Wang G., Xia Y., Harisson D., An NS2 TCP Evaluation Tool, Internet Engineering Task Force, USA, 2007.

Wei D.X., Cao P., NS-2 TCP-Linux: An NS-2 TCP Implementation with Congestion Control Algorithm from Linux, ACM, 2006.

Zegura W. E., Calvert L. K., Danahoo J. M., A Quantitative Comparison of Graph-based Models for Internet Topology, GT-ITM, 1997. 